\title{
NeW SPECIES Of genus HeRsilia Audouin, 1826 (ARANEAE: HERSILIIDAE) FROM INDIA
}

\section{G.B. Pravalikha ${ }^{1}$, Chelmala Srinivasulu $^{2} \&$ Bhargavi Srinivasulu ${ }^{3}$}

1,2,3 Wildlife Biology \& Taxonomy Lab, Department of Zoology, University College of Science, Osmania University, Hyderabad, Andhra Pradesh 500007, India

2,3 Systematics, Ecology \& Conservation Laboratory, Zoo Outreach Organization (ZOO), 96 Kumudham Nagar,

OPEN ACCESS

Vilankurichi Road, Coimbatore, Tamil Nadu 641035, India

${ }^{3}$ Biodiversity Research and Conservation Society, G4 MRK Towers, Swarnadhamanagar, Old Bowenpally, Secunderabad,

Andhra Pradesh 500011, India

${ }^{1}$ prava.gunti@gmail.com, ${ }^{2}$ hyd2masawa@gmail.com (corresponding author), ${ }^{3}$ bharisrini@gmail.com

Abstract: A new species of the genus Hersilia Audouin, 1826, Hersilia aadi sp. nov. is described from Andhra Pradesh, India with notes on the species known from India. The new species differs from its congeners based on having large palpal patella in males; and having two closely adjoining circular, small median genital openings and, long and curved copulatory duct in females.

Keywords: Andhra Pradesh, Arachnida, Hersilia aadi sp. nov., Hersilia savignyi species group, new species, Osmania University.

Abbreviations: AER - anterior eye row; ALE - anterior lateral eye; AME anterior median eye; bs - basal segment of posterior lateral spinnerets; CD - copulatory duct; d - dorsal; DMP - dorsal muscular pits; FD fertilization duct; fe - femur; $\mathrm{MOQ}$ - median ocular quadrangle; mt metatarsus; OUNHM - Osmania University Natural History Museum; p - prolateral; PER - posterior eye row; PLE - posterior lateral eye; PLS - posterior lateral spinnerets; PME - posterior median eye; Pmt - promarginal teeth; $r$ - retrolateral; Rmt - retromarginal teeth; SP spermatheca; SR - seminal receptacle; $\mathrm{Ti}$ - tibia; ts - terminal segment of posterior lateral spinnerets; TBL - total body length (carapace + abdomen); VMP - ventral muscular pits; vs. - versus; WA - anterior width of the MOQ; WP - posterior width of the MOQ.
The family Hersiliidae Thorell, 1870 comprises conspicuously long-legged, medium-sized spiders distinguished by extremely long posterior lateral spinnerets. The hersilid spiders are commonly found on tree trunks, and are known as bark spiders or two-tailed spiders. They are easily recognized by long stretched legs, raised clypeus and bi-articulation of legs I, II and IV. The family Hersiliidae consists of 15 genera and 176 species distributed worldwide (Platnick 2013) (excluding nomina dubia); the majority of the species occurs mainly in the Afro-tropical region. The genus Hersilia Audouin, 1826 of family Hersiliidae is the largest and most widely distributed ranging from Oriental to Afrotropical regions (Baehr \& Baehr 1993; Foord 2008).

Until recently, the genus Hersilia was known only by four species, namely, $H$. savignyi Lucas, 1836, $H$. sumatrana Thorell, 1890, H. striata Wang \& Yin, 1985

DOI: http://dx.doi.org/10.11609/JoTT.o3723.5553-7 | ZooBank: urn:Isid:zoobank.org:pub:984E1289-B579-4078-BEA5-7AA96D222C9C

Editor: Manju Siliwal, WILD, Coimbatore, India.

Date of publication: 26 March 2014 (online \& print)

Manuscript details: Ms \# 03723 | Received 22 July 2013 | Final received 21 February 2013 | Finally accepted 01 March 2014

Citation: Pravalikha, G.B., C. Srinivasulu \& B. Srinivasulu (2014). New species of genus Hersilia Audouin, 1826 (Araneae: Hersiliidae) from India. Journal of Threatened Taxa 6(3): 5553-5557; http://dx.doi.org/10.11609/JoTT.03723.5553-7

Copyright: @ Pravalikha et al. 2014. Creative Commons Attribution 3.0 Unported License. JoTT allows unrestricted use of this article in any medium, reproduction and distribution by providing adequate credit to the authors and the source of publication.

Funding: The study was supported by grants from Department of Biotechnology, Government of India and University Grants Commission, New Delhi

Competing Interest: The authors declare no competing interests.

Acknowledgements: We thank the Head, Department of Zoology, Osmania University, Hyderabad, for providing necessary facilities; Shri. A.V. Joseph IFS, Chief Conservator of Forests (Wildlife), Andhra Pradesh Forest Department for encouragement. We acknowledge UGC, New Delhi; DBT, New Delhi and UGC-DRS-SAP III, Deparment of Zoology, Osamania University for research grants.
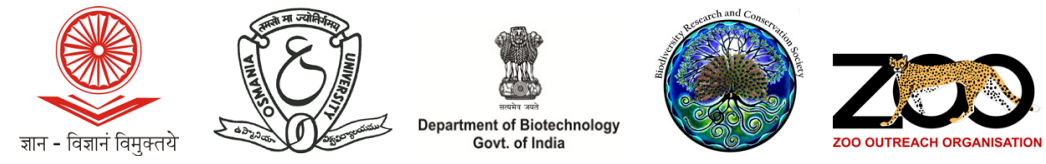
and $H$. tibialis Baehr \& Baehr, 1993, from India. Two new species, namely, H. orvakalensis Javed et al. 2010 (from Orvakal Village, Kurnool District, Andhra Pradesh) and $H$. longivulva Sen et al. 2010 (Jalpaiguri, West Bengal), were described recently. $H$. orvakalensis Javed et al. 2010 was recorded in semi urban gardens in peninsular India, while $H$. longivulva (Sen et al. 2010) was recorded from Jalpaiguri in the forested tracts near Darjeeling, West Bengal. Very little is known about their natural history excepting that they are arboreal forest dwellers (Javed \& Tampal 2010). They are assumed to have evolved from ground-dwelling hersilids (Baehr \& Baehr 1993; Rheims $\&$ Brescovit 2004). This paper gives the description of the new species of genus Hersilia from Andhra Pradesh, India.

\section{Material and Methods}

A total of 13 specimens of Hersilia sp. nov. (six males, seven females) was collected between 2010 and 2012 from the Osmania University campus $\left(17^{0} 25^{\prime} \mathrm{N}\right.$ \& $\left.78^{\circ} 31^{\prime} E\right)$, Hyderabad, Andhra Pradesh, India. Specimens were photographed with a Fujifilm super-macro digital camera in live condition, while photos of the preserved material were taken with a Sony Cybershot digital camera mounted on the eyepiece of a Lawrence and Mayo stereo zoom microscope. Line diagrams were drawn using camera lucida mounted on an Olympus stereo zoom binocular microscope.

All measurements presented are in millimeters, following Rheims \& Brescovit (2004) and Foord (2008). Only minor colour corrections were made to the pictures. The epigyne was dissected and immersed in $50 \% \mathrm{NaOH}$ solution (Barrion \& Litsinger 1995) for 24 hours to study the internal structures. The terminology used in the current paper partly follows Baehr \& Baehr (1993), Rheims \& Brescovit (2004), and Foord (2008). The specimens are deposited in the collection of the Natural History Museum of Osmania University, Hyderabad.

\section{Taxonomy}

Family Hersiliidae Thorell, 1870

Genus Hersilia Audouin, 1826

Hersilia Audouin, 1826: 317; Lucas, 1869: 1; Simon, 1893: 440; Smithers, 1945: 1; Benoit 1967: 1; Baehr \& Baehr, 1993: 3; Levy, 2003: 1; Rheims \& Brescovit, 2004: 1; Foord \& Dippenaar-Schoeman, 2006: 8; Chen, 2007: 13; Javed et al., 2010: 41.

The genus Hersilia was established by Audouin in 1826 based on $H$. caudata (see Pocock 1900).

Diagnosis: The genus Hersilia resembles the genus Murricia in having bi-articulation on legs I, II and IV, and having lateral eyes on distinct tubercles. However, it differs from the genus Murricia by the region between PME \& PLE being not tuberculated, having oval to elongated shape of abdomen, four pairs of DMP, longer legs and PLS (Chen 2007).

Type species: Hersilia caudata (Audouin, 1826)

Distribution: Ranges from Oriental to Afrotropical regions (Baehr \& Baehr 1993; Foord 2008).

\section{Hersilia aadi sp. nov.}

(Images 1-2 \& Fig. 1)

urn:Isid:zoobank.org:act:250CF397-7A3D-48CC-A4D8-C4D9921380EA

Type material: Holotype: OUNHM.ART.ARA.2011.13, male, 21.vi.2011, Osmania University campus $\left(17^{\circ} 25^{\prime} \mathrm{N}\right.$ \& 78031'E), Andhra Pradesh, India, coll. Bhargavi Srinivasulu and C. Srinivasulu. Paratype: OUNHM. ART.ARA.2011.14, female, same data as holotype. Other material: 10.v.2011, five males (OUNHM. ART. ARA.2011.15-19) and six females (OUNHM.ART.

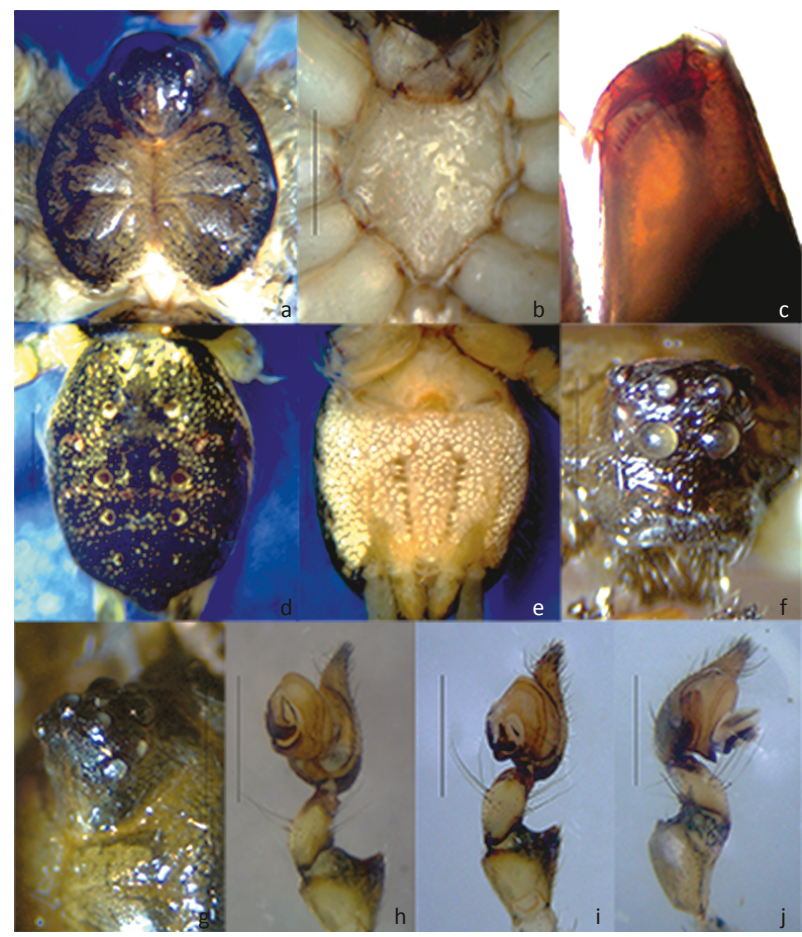

Image 1a-j. Hersilia aadi sp. nov., holotype male (OUNHM.ART. ARA.2011.13).

a - carapace, dorsal view; b - cephalothorax, ventral view; c - chelicerae, ventral view, showing three promarginal teeth and six retromarginal teeth (with an additional teeth in second row); $d$ - ocular region; e - abdomen dorsal view; f - abdomen ventral view; g - ocular region lateral view; $\mathbf{h}$ - right pedipalp ventral view; $\mathbf{i}$ - right pedipalp retrolateral view; j - right pedipalp prolateral view. Photo credits: $a-g$ - G.B. Pravalikha; $\mathbf{h}-\mathbf{j}$ - C. Srinivasulu. Scale a,b,d,e,h-j (1mm); f,g (0.5mm). 


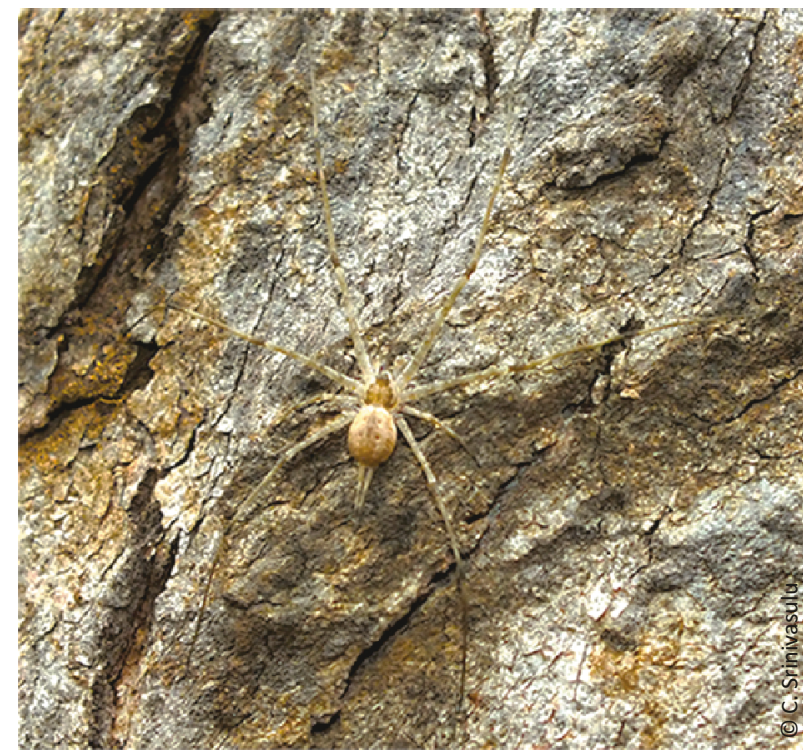

Image 2. Hersilia aadi sp. nov., live habitus image of male
ARA.2011.20-25), Osmania University campus $\left(17^{0} 25^{\prime} \mathrm{N}\right.$ \& 78 $\left.{ }^{\circ} 31^{\prime} E\right)$, Hyderabad, Andhra Pradesh, India, coll. Bhargavi Srinivasulu and C. Srinivasulu.

Diagnosis: Hersilia aadi sp. nov. belongs to the Hersilia savignyi species group which includes $H$. asiatica, $H$. striata, $H$. montana, and $H$. taiwanensis based on the presence of truncated palpal tibia. Hersilia aadi sp. nov. differs from these species in having a large male palpal patella, leg I distinctly longer than II in males, long and curved copulatory duct, and two closely adjoining circular, small median genital openings in the female vulva (Table $1 \& 2$ ). The male palp resembles that of $H$. asiatica with the presence of large conical cymbium and excavate tegular apophysis, but differs in having circular embolus and pointed almond shaped tegular apophysis.

Description: Male (Holotype, Images 1a-j, 2, Fig. 1a-c.) Habitus: Medium-sized (TBL 5.90mm), two-tailed spider with four DMP and long PLS. Colour: Carapace pale yellow, dark brown laterally; clypeus pale, white anteriorly. Sternum heart-shaped with white mottling. Legs pale yellow with dark brown bands. Abdomen

Table1. Character matrix depicting major characteristics of spiders of the $\boldsymbol{H}$. savignyi species group (Male) including $\boldsymbol{H}$. aadi sp. nov.

\begin{tabular}{|c|c|c|c|c|c|}
\hline Characteristics & H. aadi sp. nov. & H. asiatica & H. striata & H. taiwanensis & H. montana \\
\hline Chelicerae (Pmt, Rmt (L,R)) & $\begin{array}{l}\text { Pmt-3 } \\
\text { Rmt-7,6 }\end{array}$ & $\begin{array}{l}\text { Pmt-3 } \\
\text { Rmt-7,8 }\end{array}$ & $\begin{array}{l}\text { Pmt-3 } \\
\text { Rmt-6,7 }\end{array}$ & $\begin{array}{l}\text { Pmt-3 } \\
\text { Rmt-8,9 }\end{array}$ & $\begin{array}{l}\text { Pmt-3 } \\
\text { Rmt-6,7 }\end{array}$ \\
\hline $\begin{array}{l}\text { Total Body Length } \\
\text { (carapace + abdomen) }\end{array}$ & $\begin{array}{c}5.90 \\
(2.67+3.23)\end{array}$ & $\begin{array}{c}5.78 \\
(2.40+3.38)\end{array}$ & $\begin{array}{c}7.20 \\
(3.0+4.20)\end{array}$ & $\begin{array}{c}4.81 \\
(2.18+2.63)\end{array}$ & $\begin{array}{c}4.50 \\
(2.10+2.40)\end{array}$ \\
\hline Leg formula & 1243 & 1243 & 1243 & 1243 & 1243 \\
\hline Leg measurement & $\begin{array}{c}35.38 \\
30.88 \\
9.02 \\
26.27\end{array}$ & $\begin{array}{c}28.96 \\
26.93 \\
7.66 \\
22.74\end{array}$ & $\begin{array}{l}50.42 \\
40.89 \\
14.34 \\
35.63\end{array}$ & $\begin{array}{c}29.12 \\
26.86 \\
7.66 \\
21.99\end{array}$ & $\begin{array}{c}22.81 \\
22.51 \\
6.68 \\
18.38\end{array}$ \\
\hline Palp & 3.61 & 3.24 & 4.59 & 3.01 & 2.93 \\
\hline PLS total (bs+ ts) & $\begin{array}{c}4.83 \\
0.83+4.0\end{array}$ & $\begin{array}{c}4.81 \\
0.83+3.98\end{array}$ & $\begin{array}{c}8.63 \\
1.05+7.58\end{array}$ & $\begin{array}{c}4.88 \\
0.98+3.90\end{array}$ & $\begin{array}{c}4.05 \\
0.90+3.15\end{array}$ \\
\hline
\end{tabular}

Table 2. Character matrix depicting major characteristics of spiders of the $\boldsymbol{H}$. savignyi species group (Female) including $\boldsymbol{H}$. aadi sp. nov.

\begin{tabular}{|c|c|c|c|c|c|}
\hline Characteristics & H. aadi sp. nov. & H. asiatica & H. striata & H. taiwanensis & H. montana \\
\hline Chelicerae (Pmt, Rmt (L,R)) & $\begin{array}{c}\text { Pmt-3 } \\
\text { Rmt-8,6 }\end{array}$ & $\begin{array}{c}\text { Pmt-3 } \\
\text { Rmt-10,9 }\end{array}$ & $\begin{array}{c}\text { Pmt-3 } \\
\text { Rmt-7,8 }\end{array}$ & $\begin{array}{c}\text { Pmt-3 } \\
\text { Rmt-8,9 }\end{array}$ & $\begin{array}{c}\text { Pmt-3 } \\
\text { Rmt-7,8 }\end{array}$ \\
\hline $\begin{array}{r}\mathrm{MOQ} L \\
\mathrm{PA} \\
\mathrm{PW}\end{array}$ & $\begin{array}{l}0.57 \\
0.68 \\
0.52\end{array}$ & $\begin{array}{l}0.70 \\
0.66 \\
0.58\end{array}$ & $\begin{array}{l}0.76 \\
0.76 \\
0.72\end{array}$ & $\begin{array}{l}0.60 \\
0.60 \\
0.58\end{array}$ & $\begin{array}{l}0.54 \\
0.54 \\
0.54\end{array}$ \\
\hline $\begin{array}{l}\text { Total Body Length } \\
\text { (carapace + abdomen) }\end{array}$ & $\begin{array}{c}6.39 \\
(2.92+3.47) \\
\end{array}$ & $\begin{array}{c}5.63 \\
(2.48+3.15) \\
\end{array}$ & $\begin{array}{c}10.05 \\
(3.30+6.75) \\
\end{array}$ & $\begin{array}{c}6.08 \\
(2.33+3.75) \\
\end{array}$ & $\begin{array}{c}4.88 \\
(2.10+2.78) \\
\end{array}$ \\
\hline Leg formula & 2143 & 2143 & 1243 & 2143 & 2143 \\
\hline Leg measurement & $\begin{array}{c}26.87 \\
27.03 \\
9.73 \\
23.92\end{array}$ & $\begin{array}{c}18.99 \\
19.96 \\
7.21 \\
17.12\end{array}$ & $\begin{array}{l}37.14 \\
34.81 \\
11.64 \\
31.13\end{array}$ & $\begin{array}{c}19.44 \\
19.51 \\
6.61 \\
16.82\end{array}$ & $\begin{array}{c}15.68 \\
16.37 \\
5.78 \\
14.79\end{array}$ \\
\hline Palp & 4.32 & 3.38 & 5.71 & 3.46 & 2.93 \\
\hline PLS total (bs+ts) & $\begin{array}{c}6.35 \\
1.02+5.33\end{array}$ & $\begin{array}{c}5.93 \\
1.13+4.80\end{array}$ & $\begin{array}{c}10.20 \\
1.50+8.70\end{array}$ & $\begin{array}{c}5.03 \\
1.05+3.98\end{array}$ & $\begin{array}{c}4.13 \\
0.90+3.23\end{array}$ \\
\hline
\end{tabular}



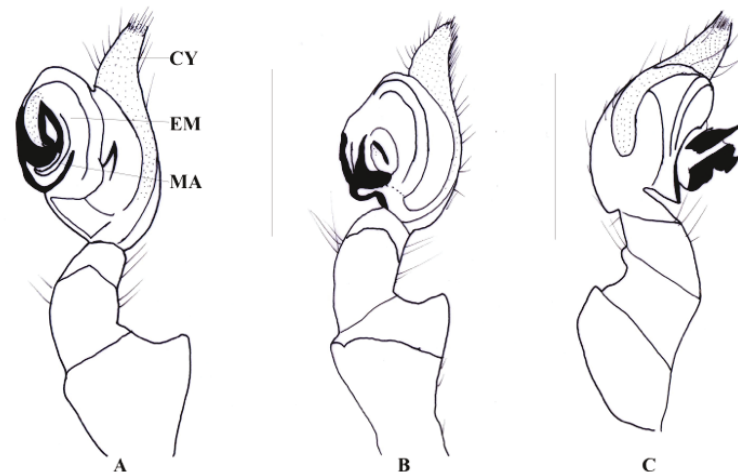

Figure $1 \mathrm{a}-\mathrm{c}$. Hersilia aadi sp. nov., line diagram of the palp (right) of holotype male (OUNHM.ART.ARA.2011.13):

a - ventral view; b - retrolateral view; c - prolateral view (EM -

Embolus; CY - Cymbium; MA - Median apophysis)

pale yellow with dark borders anteriorly; dark mid longitudinal band; abdomen broad at middle, V-shaped at the apex, pale border around dorsal muscular pits; dorsum, lateral and posterior borders of abdomen with scattered, conspicuous, dark-coloured, flat leaf- like hairs; ventrum mottled white. Carapace: Rounded, as long as wide, 2.67 long, 2.56 wide (length/width = 1.04); furnished with short hairs, some flat leaf- like hairs between AMEs and behind ocular region; fovea longitudinal with radial striae; ocular region raised, concave behind PER, AER and PER recurved, lateral eyes situated on distinct tubercles; clypeus slightly raised, furnished with long hairs; chelicerae small, 0.92 long, distal part with long hairs, Pmt with three robust, triangular teeth (the $1^{\text {st }}$ very small, the $3^{\text {rd }}$ the biggest) and Rmt with seven on the left and six minute teeth on the right side. Maxilla 0.42 long, 0.31 wide (length/ width = 1.35); labium 0.28 long, 0.44 wide (length/width =0.63); sternum 1.30 long, 1.47 wide (length/width = 0.88). Eyes: Small; lateral eyes situated on the tubercle; AME, PME and PLE black, while ALE white; MOQ 0.58 long, 0.66 WA, 0.50 WP. Eye sizes and inter distances: AME > PLE > PME > ALE $(0.26,0.18,0.16,0.08)$ and AME-AME 0.14, AME-ALE 0.15, PME-PME 0.18, PME-PLE 0.21, ALE-PLE 0.13; AER 1.12, PER 1.28; AME, largest; ALE, smallest. Legs: Leg I longest, leg III smallest. Leg formula 1243; lengths of legs [total length (femur + patella + tibia + metatarsus + tarsus) $]: I=35.38(8.73$ $+1.23+10.53+13.84+1.05) ; \|=30.88(7.52+1.11$ $+8.96+12.28+1.01) ; \mathrm{III}=9.02(2.73+0.74+2.15+$ $2.54+0.86) ; \mathrm{IV}=26.27(6.65+0.98+6.98+10.72+$ 0.94); metatarsus of legs I, II and IV is biarticulate; leg spination: I (fe 3p,3d,2r; ti 2p,4d,2r,2v; mt 1p,2d,1r,1v); II (fe 3p,3d,3r; ti 3p,2d,2r,2v; mt 1p); III (fe 2p,1r; ti $1 p, 3 d, 1 r ; m t ~ 2 p, 2 d, 2 r, 1 v$ ); IV (fe $2 p, 4 d, 2 r, 1 v$; ti 3p,3d,2r;

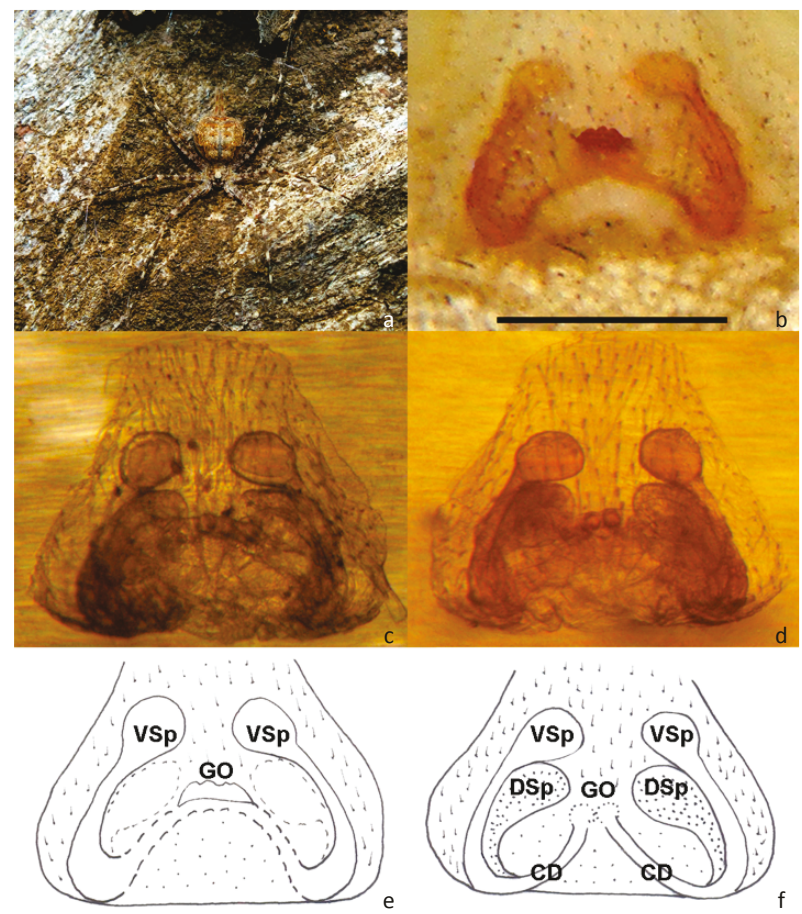

Image 3 a-f. Hersilia aadi sp. nov., paratype female (OUNHM.ART. ARA.2011.14) (scale: $0.5 \mathrm{~mm}$ ).

a - live habitus image of female; $b$ - abdomen ventral view showing epigynum on habitus; c - epigynum ventral view; $d$ - epigynum dorsal view; e - epigynum ventral view line diagram (VSp - Ventral Spermatheca; GO - Genital opening); $f$ - epigynum dorsal view line diagram (DSp - Dorsal Spermatheca; CD - Copulatory Duct; GO - Genital opening; VSp - Ventral Spermatheca).

Photo credits: a - Bhargavi Srinivasulu; b-d - G.B. Pravalikha.

mt 1p,2d,1r). Abdomen: Longer than wide, 3.23 long, 2.51 wide (length/width $=1.28$ ). Dorsally with four pairs of DMP, all pairs of DMP dissimilar in size, the second pair, the largest and fourth pair smallest. VMP arranged in a $V$ shape. PLS 4.83 long (bs 0.83 , ts 4.00 ), longer than the length of abdomen; posterior lateral spinnerets with no or faint annulation; spigots on the median border of the PLS dense and elongate. Pedipalp [total length (femur+patella+tibia+tarsus)]: $3.61(1.37+0.52+0.53+$ 1.19). Tibia short, as long as patella; patella truncated, dorsal ridge of the patella triangular and lacks spinose ridges. Cymbium conical with short and stout spines, embolus dark circular, tegular apophysis curved, narrow and apically brush-like.

\section{Description of female (Paratype, OUNHM. ART. ARA.2011.14, Images 3a-f))}

Habitus: Medium-sized (TBL 6.39mm), two-tailed spider with four DMP and long PLS. Carapace: As male, except for size. Rounded, as long as wide, 2.92 long, 2.98 wide (length/width $=0.97$ ); chelicerae small, 0.96 long, Pmt with three robust, triangular teeth and Rmt 
with eight on left and six minute teeth on the right side. Maxilla 0.59 long, 0.52 wide (length/width = 1.13); labium 0.43 long, 0.56 wide (length/width = 0.76); sternum 1.43 long, 1.65 wide (length/width $=0.86$ ). Eyes: MOQ 0.57 long, 0.68 WA, 0.52 WP. Eye sizes and inter distances: AME > PLE > PME > ALE (0.22, 0.17, $0.15,0.08$ ) and AME-AME 0.24, AME-ALE 0.17, PMEPME 0.22, PME-PLE 0.18, ALE-PLE 0.15; AER 1.18, PER 1.22; $A M E$, largest; $A L E$, smallest. Legs: Leg II longest, leg III smallest. Leg formula 2143; lengths of legs [total length (femur + patella + tibia + meta tarsus + tarsus)]: I $=26.87(7.38+1.34+6.83+9.12+1.22) ; \|=27.03(7.03$ $+1.39+6.99+10.44+1.18) ; \mathrm{III}=9.73(3.17+0.84+2.09$ $+2.52+1.11) ; \mathrm{IV}=23.92(6.47+1.11+5.64+9.61+$ 1.09; palp [total length (femur + patella + tibia + tarsus)] $=4.32(1.35+0.73+0.86+1.38)$; metatarsus of legs $\mathrm{I}$, II and IV is bi-articulate; leg spination: I (fe 4p,3d,3r; ti $2 p, 3 d, 2 r, 1 v ; m t 1 d, 1 r) ;$ II (fe 3p,2d,3r; ti 3p,2d,2r; mt 1p); III (fe 3p,2d,2r,1v; ti 2d,1r; mt 1p,1d); IV (fe 3p,3d,2r; ti $2 p, 2 d, 1 r ; m t 2 p, 2 d, 2 r)$. Abdomen: Almost as wide as long, 3.47 long, 3.26 wide (length/width =1.06). Dorsally with four pairs of DMP, all pairs of DMP dissimilar in size, the second pair the largest and fourth pair smallest. VMP arranged in a V shape. PLS 6.35 long (bs 1.02, ts 5.33), nearly double the length of abdomen; posterior lateral spinnerets with no or faint annulation; spigots on the median border of the PLS dense and elongate. Epigyne: Epigyne weakly sclerotized, two pairs of spermathecae, ventral spermathecae small oval-shaped with long curved copulatory duct, dorsal spremathecae large elliptical-shaped; two copulatory openings; ventral spermathecae visible through tegument.

\section{Etymology}

The specific epithet is a noun in apposition taken from the Sanskrit word 'aadi' meaning 'first'.

\section{Distribution}

Presently known only from the type locality, Osmania University campus $\left(17^{\circ} 25^{\prime} \mathrm{N} \& 7^{\circ} 31^{\prime} \mathrm{E}\right)$, Hyderabad, Andhra Pradesh, India.

\section{Natural History}

The type specimens were collected on the bark of the Azadirachta indica and Polyalthia cerasoides trees in the Osmania University campus, Hyderabad. Many specimens of the new species described in this paper have been observed in the Osmania University Campus and other urban gardens. As opined by Javed \& Tampal (2010), we feel that the species diversity in the family Hersilidae is under-represented and future research will result in discovery of new species.

\section{References}

Audouin, V. (1826). Explication sommaire des planches d'arachnides de I'Egypte et de la Syrie publiées. In: Description de l'Egypte, Histoire Naturelle, Paris: 404, illustrations t 7, $\mathrm{f} 8$. (this description is also quoted as published in 1825 and 1827).

Baehr, M. \& B. Baehr (1993). The Hersiliidae of the Oriental Region including New Guinea. Taxonomy, phylogeny, zoogeography (Arachnida, Araneae). Spixiana (Suppl.) 19: 1-96.

Barrion, A.T. \& J.A. Litsinger (1995). Riceland Spiders of South and Southeast Asia. CAB International, Wallingford, UK, xix+700pp.

Benoit, P.L.G. (1967). Révision des espèces africaines du genre Hersilia Sav. et Aud. (Aran.-Hersiliidae). Revue de Zoologie et de Botanique africaines 76: 1-36.

Chen, S.H. (2007). Spiders of the genus Hersilia from Taiwan (Araneae: Hersiliidae). Zoological Studies 46: 12-25.

Foord, S.H. \& A.S. Dippenaar-Schoeman (2006). A revision of the Afrotropical species of Hersilia Audouin (Araneae: Hersiliidae). Zootaxa 1347: 1-92.

Foord, S.H. (2008). Cladistic analysis of the Afrotropical Hersiliidae (Arachnida, Araneae) with the first record of Murricia and the description of a new genus from Madagascar. Journal of Afrotropical Zoology 4: 111-142.

Javed, S.M.M., S.H. Foord \& F. Tampal (2010). A new species of Hersilia Audouin, 1826 (Araneae: Hersiliidae) from India, with notes on its natural history. Zootaxa 2613: 40-50.

Javed, S.M.M. \& F. Tampal (2010). Spiders of the genus Murricia Simon, 1882 (Araneae: Hersiliidae) from India. Acta Zoologica Lituanica 20(2): 88-97; http://dx.doi.org/10.2478/v10043-010-0012-9

Levy, G. (2003). Spiders of the families Anyphaenidae, Hahniidae, Ctenidae, Zoridae, and Hersiliidae (Araneae) from Israel. Israel Journal of Zoology 49(1): 1-31; http://dx.doi.org/10.1560/X05JTOMU-UL4A-8RLQ

Lucas, H. (1836). Observations sur les Araneae du genre Hersilia et description de deux especes nouvelles appurtenant a ce genre. Guerin's Magazine Zoology 6: 1-11.

Lucas, H. (1869). Quelques remarques sur les articles additionnels observés dans les palpes des Actinopus, les pattes des Hersilia et description d'une nouvelle espèce d'aranéide appartenant à cette dernière coupe générique. Revue Magasin de Zoologie 2: 160-170.

Platnick, N.I. (2013). The World Spider Catalog. Version 13.5. American Museum of Natural History. Available from: http://research.amnh. org/iz/spiders/catalog/HERSILIIDAE.html. (Accessed 17 June 2013)

Pocock, R.I. (1900). The Fauna of British India, Including Ceylon and Burma. Arachnida. Taylor and Francis, London, 279pp.

Rheims, C.A. \& A.D. Brescovit (2004). Revision and cladistic analysis of the spider family Hersiliidae (Arachnida, Araneae) with emphasis on Neotropical and Nearctic species. Insect Systematics and Evolution 35(2): 189-239; http://dx.doi.org/10.1163/187631204788912355

Sen, S., S. Saha \& D. Raychaudhuri (2010). Two tailed spiders (Araneae: Hersilidae) from the reserve forests of North Bengal, India. Munis Entomology and Zoology 5(suppl.): 1168-1175.

Simon, E. (1893). Histoire naturelle das araignées. Paris, I, 257-488pp. Smithers, R.H.N. (1945). The Hersiliidae (Araneae) of South Africa. Transactions of the Royal Society of South Africa 31(1): 1-18; http:// dx.doi.org/10.1080/00359194509520547

Thorell, T. (1870). On European spiders. Nova Acta Regiae Societatis Scientiarum Upsaliensis 7: 109-242.

Thorell, T. (1890). Studi sui ragni Malesi e Papuani. IV, 1. Annali del Museo civico di storia naturale di Genova 28: 1-419.

Wang, J.F. \& C.M. Yin (1985). Two new species of spiders of the genus Hersilia from China (Araneae: Hersiliidae). Acta Zootaxonomica Sinica 10: 45-49.

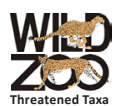

